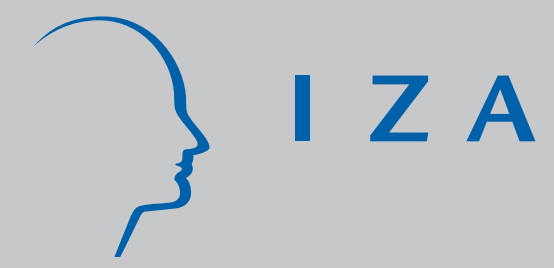

IZA DP No. 1414

Works Councils, Labor Productivity and Plant Heterogeneity:

Evidence from Quantile Regressions

J oachim Wagner

J ohn T. Addison

Claus Schnabel

Thorsten Schank

November 2004 


\title{
Works Councils, Labor Productivity and Plant Heterogeneity: Evidence from Quantile Regressions
}

\author{
Joachim Wagner \\ University of Lueneburg \\ and IZA Bonn \\ John T. Addison \\ University of South Carolina, \\ GEMF, University of Coimbra and IZA Bonn \\ Claus Schnabel \\ University of Erlangen-Nuremberg \\ Thorsten Schank \\ University of Erlangen-Nuremberg
}

Discussion Paper No. 1414

November 2004

IZA

P.O. Box 7240

53072 Bonn

Germany

Phone: +49-228-3894-0

Fax: +49-228-3894-180

Email: iza@iza.org

Any opinions expressed here are those of the author(s) and not those of the institute. Research disseminated by IZA may include views on policy, but the institute itself takes no institutional policy positions.

The Institute for the Study of Labor (IZA) in Bonn is a local and virtual international research center and a place of communication between science, politics and business. IZA is an independent nonprofit company supported by Deutsche Post World Net. The center is associated with the University of Bonn and offers a stimulating research environment through its research networks, research support, and visitors and doctoral programs. IZA engages in (i) original and internationally competitive research in all fields of labor economics, (ii) development of policy concepts, and (iii) dissemination of research results and concepts to the interested public.

IZA Discussion Papers often represent preliminary work and are circulated to encourage discussion. Citation of such a paper should account for its provisional character. A revised version may be available directly from the author. 
IZA Discussion Paper No. 1414

November 2004

\section{ABSTRACT}

\section{Works Councils, Labor Productivity and Plant Heterogeneity: Evidence from Quantile Regressions*}

Using quantile regressions and a rich cross section data set for German manufacturing plants, this paper reports that the impact of works councils on labor productivity varies along the conditional distribution of value added per employee. It emerges that the positive and statistically significant effect of works council presence estimated by ordinary least squares now vanishes for large parts of this distribution. According to our results, such an effect can only be detected in plants at the top end of the conditional productivity distribution - plants that can be considered 'over achievers.' We would speculate that this might be because only highly competent managers can cooperate with a works council in a way that much enhances productivity.

JEL Classification: $\quad J 50$

Keywords: labor productivity, works councils, quantile regressions, heterogeneous firms

Corresponding author:

Joachim Wagner

Institute of Economics

University of Lueneburg

Campus 4.210

21332 Lueneburg

Germany

Email: wagner@uni-lueneburg.de

\footnotetext{
${ }^{*}$ The authors thank Roger Koenker for helpful advice.
} 


\section{Motivation}

In Germany, workers in establishments with at least five employees have the right to elect a works council. Works councils have information, consultation, and codetermination rights. These rights, as well as the number of councilors - both full-time and part-time - are increasing in establishment size (measured by the number of employees). Note that works councils while mandatory are not automatic and, as a practical matter, their presence is sporadic in smaller establishments and near universal in large plants with 500 workers or more (for details, see Addison, Bellmann, Schnabel and Wagner 2004).

In theory, works councils can be expected to have both positive and negative impacts on various dimensions of firm performance, such as labor productivity and profitability. The reason resides in the two faces of works councils: On the one hand, works councils can use their powers to delay or modify management decisions and shift rents to the employees. On the other hand, they can also improve the efficiency of the establishment through productive information exchange, consultation, and codetermination. A canonical reference for the theoretical discussion of these issues is the Freeman and Lazear (1995) model that extends the well-known workplace union collective voice arguments of Freeman and Medoff (1984) to the specific case of works councils.

It follows that establishing the direction and extent of works councils' net impact on economic performance is an empirical question. The econometric literature on German works councils is a work in progress, so that there is ongoing debate as to the consequences of the institution (for a comprehensive survey, see Addison, Schnabel and Wagner 2004). One problem that has not yet been dealt with in a convincing way is unobserved heterogeneity: plant diversity that is not reflected in the control variables used in the economists' models used to investigate the cet. par. relationship between works council presence and the relevant performance indicator. 
To fix ideas, and to set the scene for the present inquiry, consider a core dimension of plant performance that has been investigated in the empirical literature on works councils: establishment labor productivity, as measured as the average value added per employee. A standard approach has been to estimate a single-equation model with productivity as the dependent variable and a set of factors that are related to productivity (e.g., percentage of skilled employees, hours worked per week, etc.) plus a dummy variable indicating the presence or otherwise of a works council as independent variables. Consider now the role of a variable that is not included in the set of determinants of productivity in the empirical model, namely, management competence. This omitted variable can be expected to have an impact on all dimensions of plant performance, including labor productivity. Highly-able managers will organize the production process in such a way that leads to rather high values of labor productivity for a given set of establishment characteristics, and conversely in the case of bad managers. In short, conditional on the productivity-determining characteristics of an establishment included in the empirical model there will be over achievers (with able managers) and under performers (with incompetent managers). ${ }^{1}$

Competence of the management is a variable for which no measure (or proxy) is readily available from the surveys used to investigate the works council-labor productivity nexus, and unmeasured management competence leads to unobserved establishment heterogeneity. The standard tools used in econometrics to control for unobserved heterogeneity can not be used in this context for two reasons: First, the extant longitudinal data sets include only a small number of establishments that introduce or abandon works councils (see Addison, Bellmann, Schnabel and Wagner 2004), meaning that estimated coefficients from fixed effects models are unreliable. Second, unobserved management quality and some of the determinants of

\footnotetext{
${ }^{1}$ The terms over achievers and under performers are borrowed from a study on cross-country differences in economic growth by Barreto and Hughes (2004) that also uses quantile regression methods.
} 
labor productivity included in the empirical model tend to be correlated, so that coefficient estimates from random effects models are biased.

Unmeasured management competence is not the only source of unobserved establishment heterogeneity. There are other variables that are relevant for productivity for which no information is available in survey data; the principal case in point for the dataset used here is the value of the capital stock, information on which could not be collected in interviews with the owner or manager.

If we acknowledge that establishments are heterogeneous in the sense discussed above, we have good reason to suspect that the effects of the variables included in an empirical model to explain labor productivity do not need to be the same for all firms. Consider the way managers and works councils interact. In Germany, works councils are sometimes regarded as factors of production or as 'co-managers.' It might well be the case that highly competent managers will cooperate with a works council in a way that materially enhances productivity; while incompetent managers will fail here, too. In these circumstances, a positive impact of works councils will be found in over-achieving establishments (i.e., in plants that, conditional on their observed characteristics, have a rather high labor productivity), while either no effect or a negative effect will be present in under-performing establishments.

If we are interested in the relationship between labor productivity on the one hand and a set of plant characteristics (such as works council presence, size, skill intensity, etc.) on the other, and if we regress labor productivity on these independent variables using ordinary least squares (OLS), there is no room for plant heterogeneity of the kind discussed here. OLS assumes that the conditional distribution of labor productivity, given the set of plant characteristics, is homogeneous. This implies that no matter what point on the conditional distribution is analyzed, the estimates of the relationship between labor productivity (the dependent variable) and the plant characteristics (the independent variables) are the same. If one wants to test the empirical validity of this rather restrictive assumption, and if one is 
interested in the evaluation of the relative importance of the variables viewed as determining labor productivity at different points of the conditional distribution of labor productivity, one has to apply a different estimation technique that is tailor-made for this: quantile regression.

A discussion of the technical details of quantile regression is beyond the scope of this paper. The basic references are the pioneering study by Koenker and Bassett (1978) and the survey by Buchinsky (1998). (Koenker and Hallock, 2001, provide a useful non-technical introduction.) Suffice it to say here that in contrast to OLS (that gives information about the effects of the regressors at the conditional mean of the dependent variable only) quantile regression can provide parameter estimates at different quantiles of the conditional distribution of productivity. The estimated regression coefficients can be interpreted as the partial derivative of the conditional quantile of the dependent variable (here, labor productivity in a plant) with respect to a particular regressor (e.g., the presence or otherwise of a works council), namely, the marginal change in labor productivity at the $\mathrm{k}^{\text {th }}$ conditional quantile due to a change in the works council status of the plant. For each quantile it can be shown whether the effect of a particular regressor is positive or negative, and how large this effect is compared to other quantiles. This method provides information about the heterogeneity of plants. Note that quantile regression is not the same as applying OLS to subsets of the data produced by dividing the complete data set into different percentiles of the dependent variable. This would mean that not all of the data are being used for each estimate, and it would introduce the familiar type of sample selection bias. For each quantile regression estimate all of the data are being used, although some observations do get more weight than others.

This paper contributes to the literature on works councils' effects by for the first time applying quantile regression methods to the study of the relationship between labor 
productivity and works council presence. ${ }^{2}$ Our discussion is organized as follows. Section 2 gives information on the plant-level data and the empirical model used. Section 3 reports and comments on the findings from the econometric investigation. And section 4 concludes.

\section{Data and empirical model}

The data used in this paper were collected in interviews conducted as part of a panel study, Das Hannoveraner Firmenpanel, investigating various aspects of firm behavior and firm performance. The population covered encompasses all manufacturing establishments with at least 5 employees in 1994 in the state of Lower Saxony. The data were collected in personal interviews with the owner or top manager of the firm. Details of the data set and how it can be accessed by researchers is given in Gerlach, Hübler, and Meyer (2003).

The empirical model used here to investigate the relationship between labor productivity and the presence or not of a works council is taken from an earlier contribution by (three of) the present authors that investigated the effects of works councils on various aspects of establishment performance (see Addison, Schnabel and Wagner 2001). The dependent variable considered here is labor productivity, proxied by value added per employee. As independent variables, and in addition to a dummy variable for works council presence, we include establishment size (number of employees) and its square as well as the status of the establishment as a branch plant to pick up possible internal and external factors conveying organizational and scale advantages. The productivity effects of human capital are captured by three variables describing the employment structure: the shares of females, skilled blue-collar workers, and academically-trained workers in employment. Another regressor, the

\footnotetext{
${ }^{2}$ Although they have not been deployed previously in the works council literature, quantile regressions have been used in a number of firm productivity studies. Examples include analyses of the productivity effects of foreign ownership in Greece (Dimelis and Louri, 2002),
} 
proportion of part timers, is mechanically linked to value-added per head. The modernity of the physical capital stock is expected to lead to higher productivity, and the same holds for higher capacity utilization, a longer work week, the presence of shiftworking, and enhanced market share (i.e., price setting power). Dummy variables for the presence or otherwise of profit sharing schemes for both workers and managers are included to model any tendency they might have to stimulate higher productivity. Finally, we control for the age of the establishment, and for industry affiliation.

Given that the survey data set used here does not have information on either the physical capital stock of the establishment or the physical output produced, our findings must necessarily be viewed with some caution. Nevertheless, the data are rich enough to help us to learn more about the variation of the productivity-works council relationship along the conditional distribution of value added per employee. ${ }^{3}$

\section{Results of the econometric investigation}

As a benchmark, in the first step of our econometric investigation the empirical model was estimated by OLS, replicating the results reported in our earlier study (see Addison, Schnabel and Wagner 2001, Table 3). Results are reported in the first column of Table $1 .^{4}$ Given our focus on the relationship between productivity and works councils, we do not comment on the results for the other variables (see the earlier study mentioned above) and simply point out

of exporting in Turkey (Yasar, Nelson, and Rejesus, 2003), and of teleworking in Denmark (Kaiser, 2004).

${ }^{3}$ Over-achieving plants may be expected to have a higher physical capital stock, but there is no reason to believe that the impact of a works council on productivity varies with the capital stock.

4 These results differ slightly from those reported earlier. We were unable to replicate the old estimations exactly since these were performed in 1997 using an earlier release of the first 
that the coefficient estimate of the works council dummy variable is positive and statistically significant (at an error level of 1.3 percent). Furthermore, the point estimate indicates that value added per employee is some 16,000 DM (or about EUR 8,000) higher in establishments with a works council compared to those without.

\section{[Table 1 near here]}

To repeat, application of OLS implies that, no matter what point on the conditional distribution is analyzed, the estimates of the relationship between labor productivity and the plant characteristics is the same. To test the empirical validity of this rather restrictive assumption, and to uncover the relative importance of the variables viewed as determining labor productivity at different points of the conditional distribution of value added per employee, quantile regression estimation is applied in a second step. We examine five points in the distribution, namely, at the $0.10,0.25,0.50,0.75$, and 0.90 quantile. Results are reported in columns two through six of the table.

The point estimates and the statistical significance of the coefficient estimates for the works council dummy variable differ widely across the regressions for the various quantiles, and vis-à-vis to the benchmark results from the OLS regression. They are positive but much smaller than in the OLS regression for all but the highest quantile investigated. Indeed, the works council coefficient estimate is statistically significant at conventional levels only for establishments at the very top of the conditional distribution of productivity. The null hypotheses that the coefficients of the works council dummy variable are equal between pairwise quantiles and across all quantiles may be tested based on the variance-covariance matrix of the coefficients of the system of quantile regressions reported in Table 1 . Table 2 gives the prob-values for the computed F-statistics. The null hypothesis is rejected at an error

wave of the Hannover Firm Panel and DOS-Versions of SPSS-PC and SHAZAM which are no longer available to us. All computations for this paper used Stata/SE 8.2 . 
level of 8.5 percent for the 0.50 vs. the 0.90 quantile, and at an error level of 3.1 percent for the 0.75 vs. the 0.90 quantile.

[Table 2 near here]

Contrary to the results from the OLS regression, therefore, quantile regressions point to a positive impact of works councils in over-achieving establishments alone (i.e., in plants that, conditional on their observed characteristics, have a very high labor productivity), while no statistically significant effect is recorded for the rest of the plants. ${ }^{5}$

To learn more about these over- and under-achieving plants, and about the establishments located at the other points of the conditional distribution of labor productivity, we computed descriptive statistics for the plants at the $0.10,0.25,0.50,0.75$, and 0.90 quantile. ${ }^{6}$ It is interesting to know, for instance, whether all the over-achieving plants do have a works council, or whether they are predominantly large firms. The results are reported in Table 3.

[Table 3 near here]

The important thing that we learn from these results is that establishments at the 0.90 quantile - where the works council effect is positive and both statistically and economically

\footnotetext{
${ }^{5}$ In our earlier study, we also looked at a sub-sample of all establishments with 21-100 employees, because in this size class works council rights (that increase discontinuously with the number of employees in a plant) are a datum. Contrary to the results from the OLS estimation using data for all establishments, we found no well-determined link between productivity and works council presence for this sub-sample of smaller firms (see Addison, Schnabel and Wagner 2001, Table 3). Quantile regression estimates for the sub-sample also failed to reveal a statistically significant impact of works councils for any quantile. Details are are available on request from the authors.

${ }^{6}$ Establishments at the 0.90 quantile are those observations that have zero residuals based on the estimates for this quantile. For a fitted quantile regression model with p parameters (in our case, $p$ is equal to 47) there are, by construction, always $p$ basic observations that will have
} 
significant - are not all large plants and do not all have a works council. Indeed, to the contrary, the share of plants with a works council is smaller than in the sample as a whole and at the other points in the distribution considered, while the average number of employees is smaller than at the 0.50 and 0.75 quantiles. Therefore, as suggested earlier, our central finding of a positive impact of works councils in over-achieving establishments alone (i.e., in plants that, conditional on their observed characteristics, have a very high labor productivity) might be the due to the fact that only highly competent managers of over-achieving establishments tend to cooperate with a works council in a way that materially enhances productivity.

We note in passing that large differences in the point estimates and levels of significance as between the various quantiles, and compared to the benchmark OLS results, can also be found for some of the other determinants of productivity. Cases in point are the branch plant status, plant age, percentage of employees with an academic degree, shift work, and profit sharing for management. Vulgo: heterogeneity abounds.

\section{Concluding remarks}

Using quantile regression methods and a rich cross-section data set for German manufacturing plants, this paper demonstrates that the impact of works council presence on labor productivity varies along its conditional distribution. We would speculate that this might be because only highly competent managers can cooperate with a works council in a way that much enhances productivity. Our empirical finding points to the need to supplement OLS (or any other econometric method that focuses on the conditional mean of a dependent variable) by quantile regressions when investigating the behavior of heterogeneous plants. To put it differently, and to quote Buchinsky (1994, p. 453): “'On the average' has never been a satisfactory statement with which to conclude a study on heterogeneous populations."

zero residuals at a solution. We thank Roger Koenker for pointing this out (in private email on November 8, 2004). 


\section{References}

Addison, J. T., Bellmann, L., Schnabel, C., Wagner, J., 2004. The reform of the German works constitution act: A critical assessment. Industrial Relations 43, 392-420.

Addison, J. T., Schnabel, C., Wagner, J., 2001. Works councils in Germany: their effects on establishment performance. Oxford Economic Papers 53, 659-694.

Addison, J. T., Schnabel, C., Wagner, J., 2004. The course of research into the economic consequences of German works councils. British Journal of Industrial Relations 42, 255-281.

Barreto, R. A., Hughes, A. W., 2004. Under performers and over achievers: a quantile regression analysis of growth. Economic Record 80, 17-35.

Buchinsky, M., 1994. Changes in the U.S. wage structure 1963 - 1987: application of quantile regression. Econometrica 62, 405-458.

Buchinsky, M., 1998. Recent advances in quantile regression models. A practical guideline for empirical research. Journal of Human Resources 33, 88-126.

Dimelis, S., Louri, H., 2002. Foreign ownership and production efficiency: a quantile regression analysis. Oxford Economic Papers 54, 449-469.

Freeman, R. B., Medoff, J.L., 1984. What do unions do? New York: Basic Books.

Freeman, R. B., Lazear, E. P., 1995. An economic analysis of works councils. In Rogers, J., Streeck, W. (Eds.), Works councils - Consultation, representation, and cooperation in industrial relations. Chicago: University of Chicago Press, 27-52.

Gerlach, K., Hübler, O., Meyer, W., 2003. The Hannover Firm Panel (HFP). Schmollers Jahrbuch / Journal of Applied Social Science Studies 123, 463-470.

Kaiser, U., 2004. Is there really no place like home for productivity? Centre for Economic and Business Research CEBR Discussion Paper 2004-06, Copenhagen, February.

Koenker, R., Bassett, G., 1978. Regression quantiles. Econometrics 46, 33-50. 
Koenker, R., Hallock, K. F., 2001. Quantile regression. Journal of Economic Perspectives 15, Fall, 143-156.

Yasar, M., Nelson, C.H., Rejesus, R., 2003. Productivity and exporting status of manufacturing firms: evidence from quantile regressions. Emory University Department of Economics Working Paper 03-23, October. 


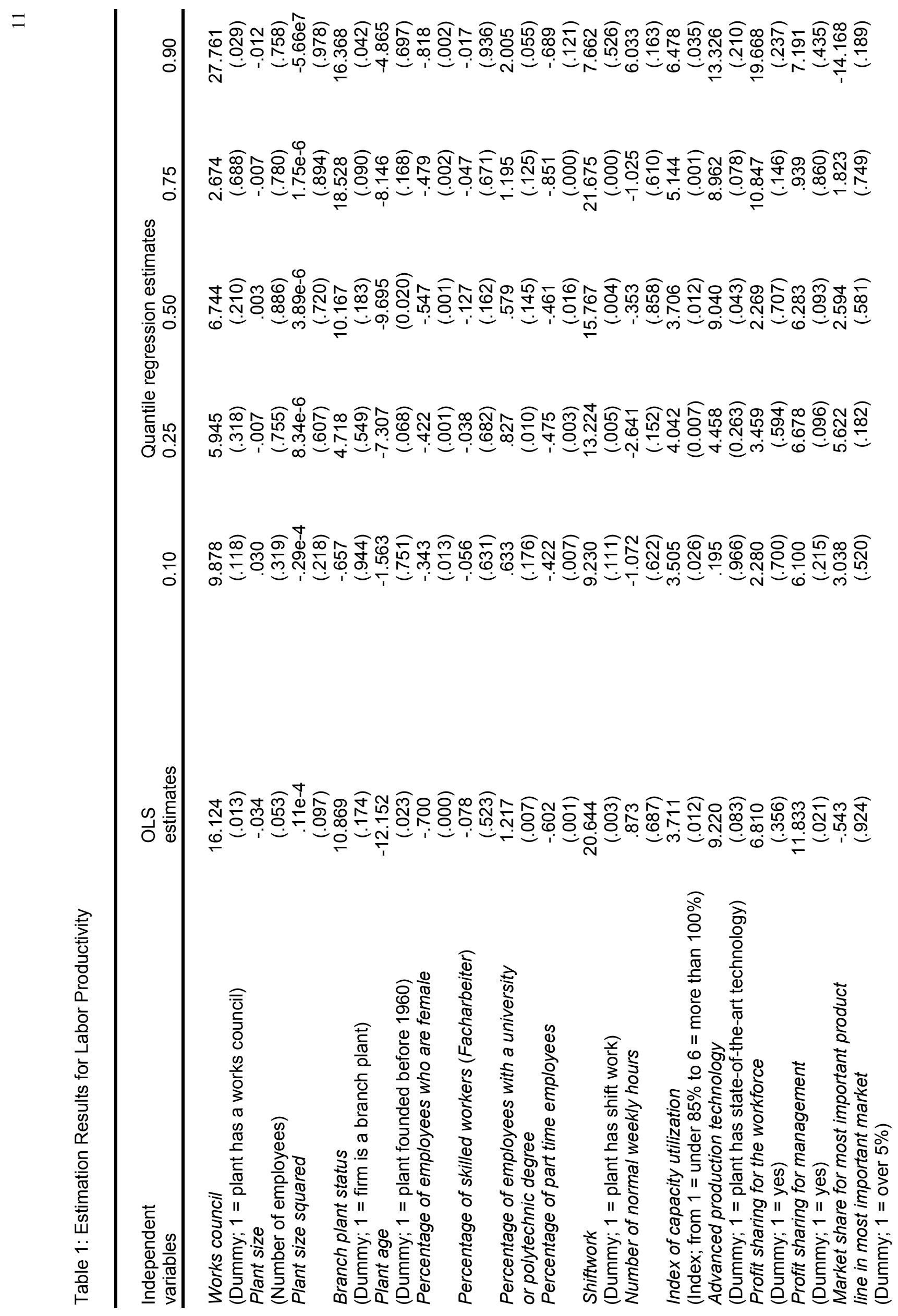


$\simeq$

$$
\begin{aligned}
& \text { กิ้ พิษ } \\
& \text { ণ্ }
\end{aligned}
$$

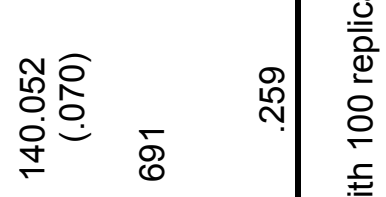

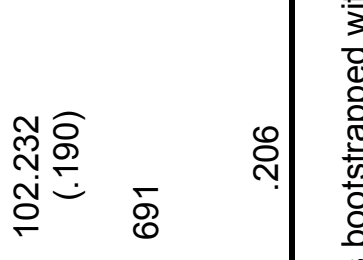

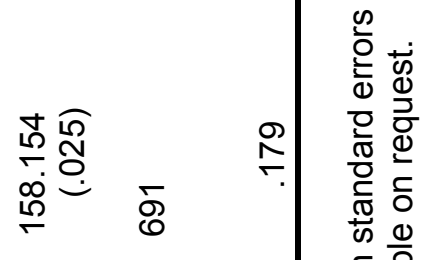

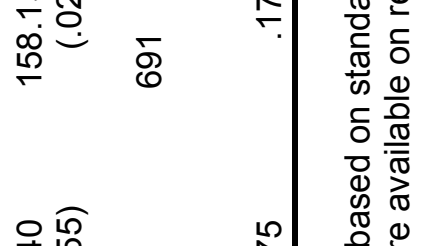

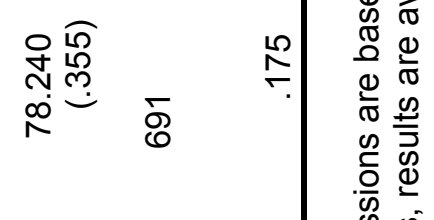

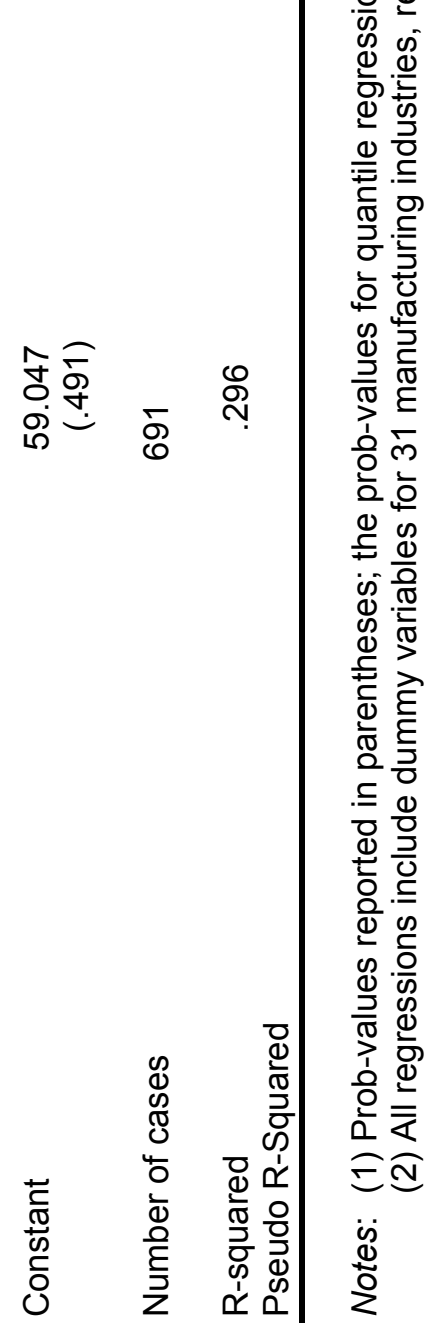




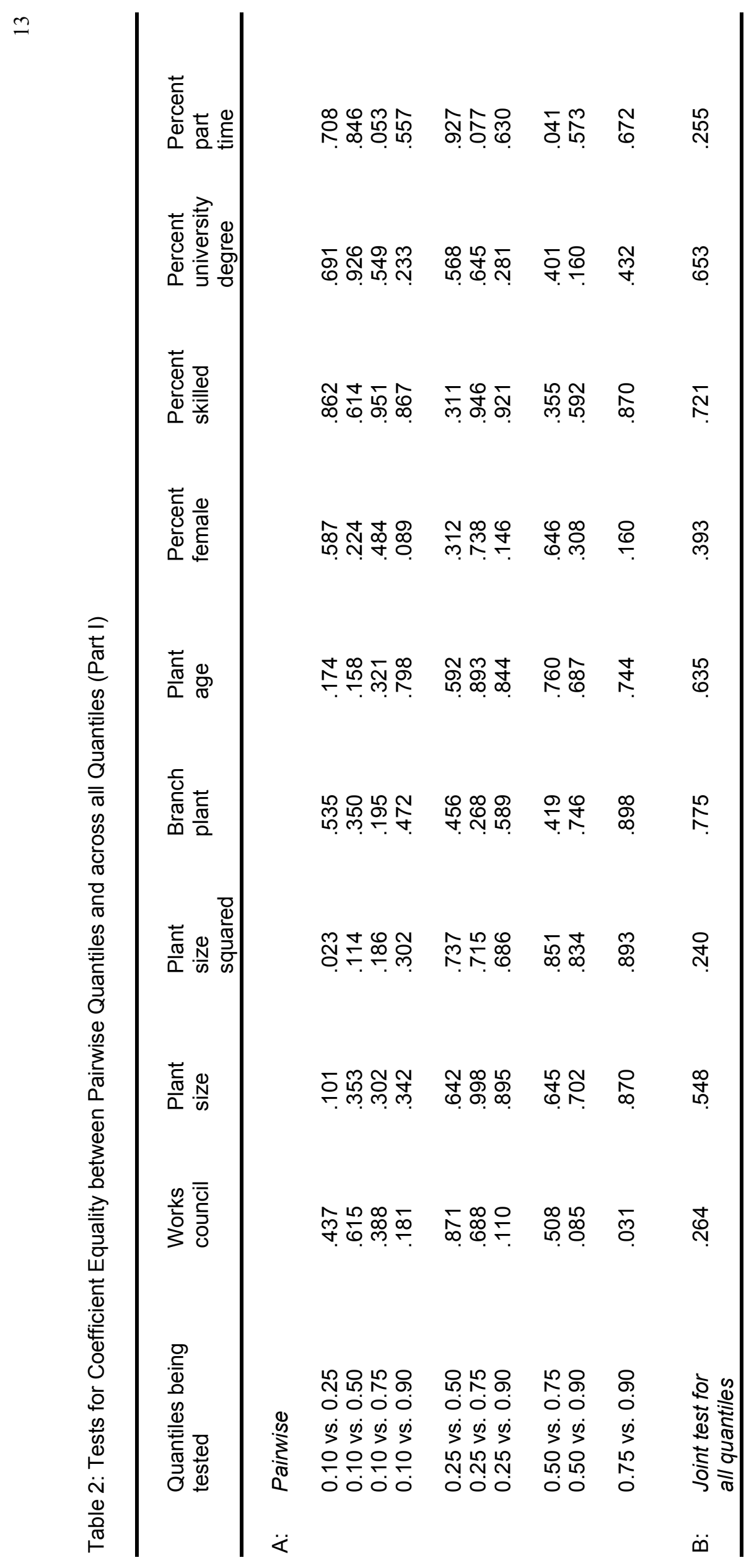




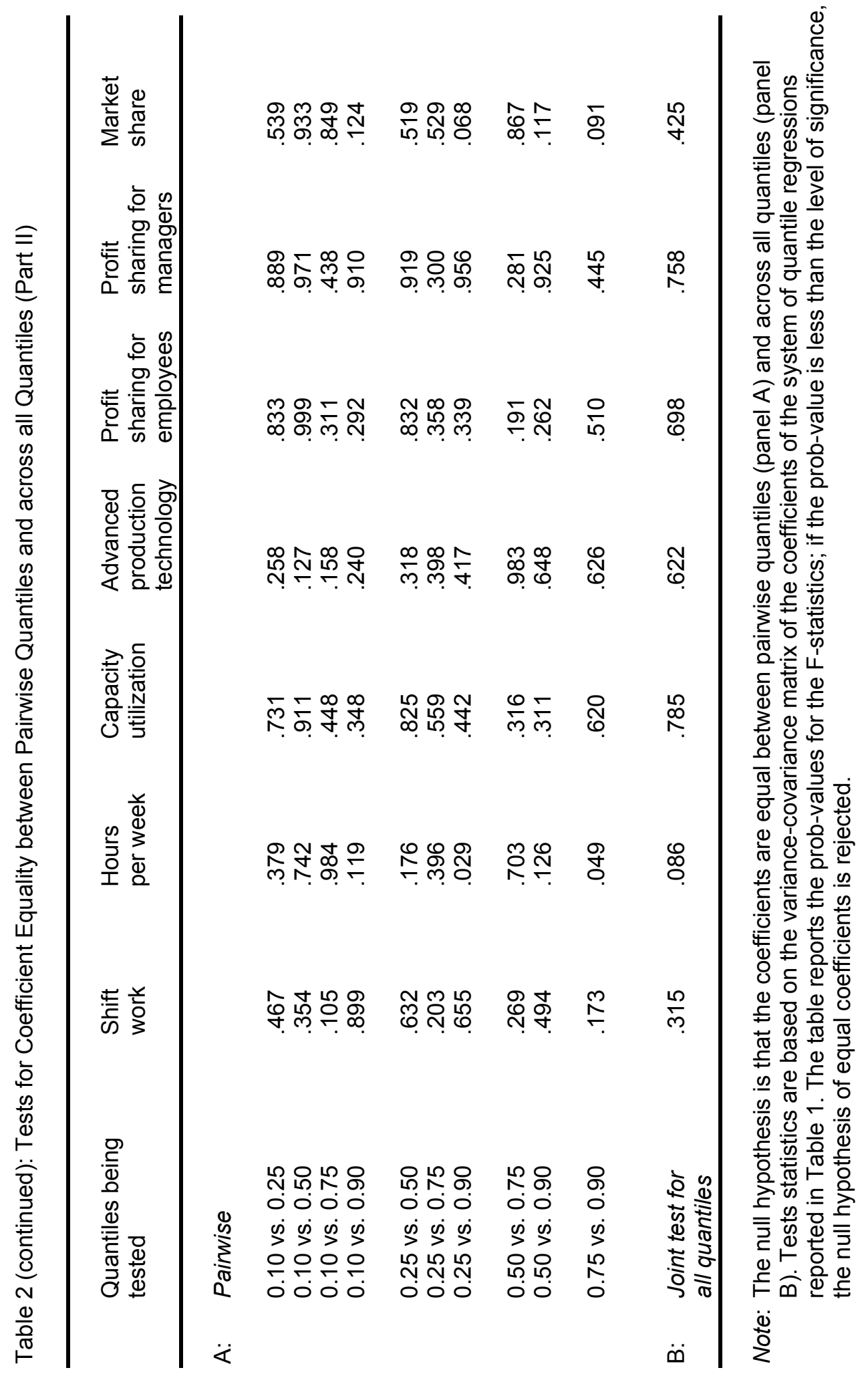


ㄴ

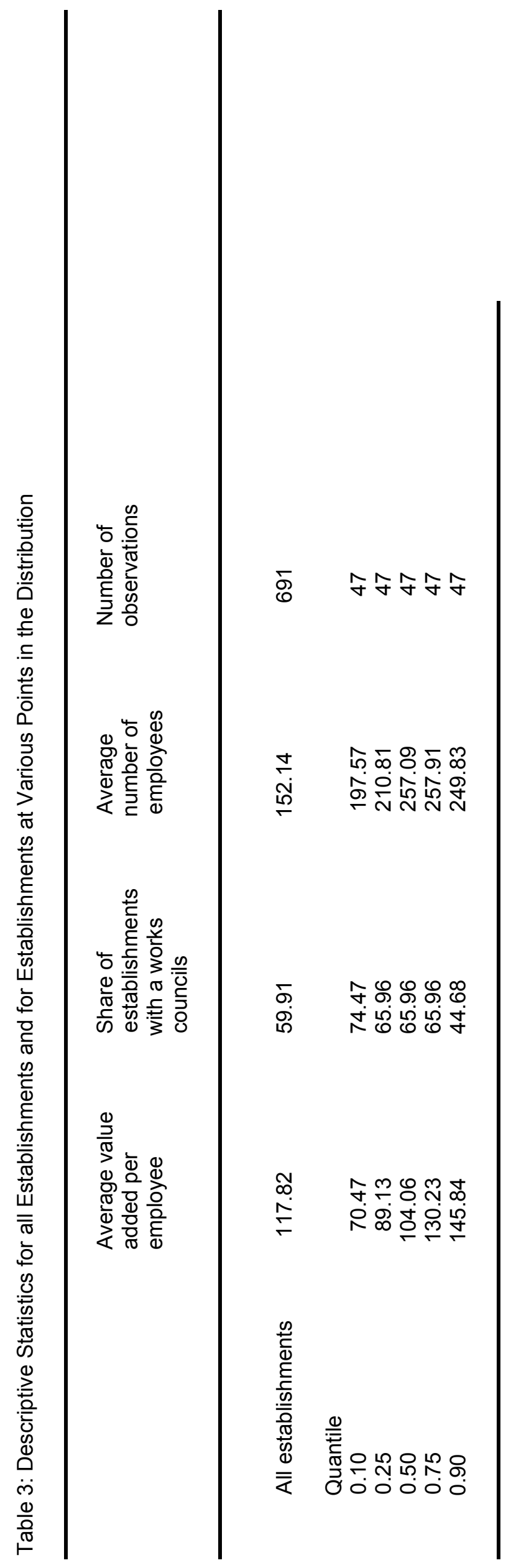

